\title{
EFFECT OF ETHYL SILICATE ON THE WATER RESISTANCE OF MAGNESIUM OXYCHLORIDE CEMENT
}

\author{
HUANG QING*, **,***, LI YING*,**, WEN JING*,**, ZHENG WEIXIN*, **, ***, CHANG CHENGGONG*, **, \\ DONG JINMEI*, ${ }^{* *}$, A DANCHUN*, $* *, * * *,{ }^{*}$ XIAO XUEYING*, $* *$, ZHOU YUAN*, ** \\ *Key Laboratory of Comprehensive and Highly Efficient Utilization of Salt Lake Resources, Qinghai Institute of Salt Lakes, \\ Chinese Academy of Sciences, No. 18, Xinning Road, Xining 810008, P.R. China \\ **Key Laboratory of Salt Lake Resources Chemistry of Qinghai Province, No. 18, Xinning, \\ Xining 810008, P.R. China \\ ***University of Chinese Academy of Sciences, No. 19, Yuquan Road, \\ Beijing 100049, P.R. China
}

\#E-mail: xueyingxiao012@163.com

Submitted April 28, 2019; accepted September 26, 2019

\begin{abstract}
Keywords: Magnesium oxychloride cement, Water resistance, Ethyl silicate, Micro structure
In this paper, fly ash (FS), phosphoric acid $\left(\mathrm{H}_{3} \mathrm{PO}_{4}\right)$, ferrous sulfate $\left(\mathrm{FeSO}_{4} \cdot 7 \mathrm{H}_{2} \mathrm{O}\right)$ and ethyl silicate (TEOS) were incorporated to devote effort for the further improvement of the water resistance of magnesium oxychloride cement (MOC). The strength retention coefficient was tested to evaluate the water resistance of the MOC, in which the addition of $\mathrm{FS}+\mathrm{H}_{3} P \mathrm{O}_{4}+$ $+\mathrm{FeSO}_{4} \cdot 7 \mathrm{H}_{2} \mathrm{O}+\mathrm{TEOS}$ resulted in a remarkable improvement. The characterisation of the hydration products before and after the water immersion was carried out using X-ray diffraction (XRD), a thermogravimetric (TG) analysis, Fourier-transformed infrared spectroscopy (FTIR) and a scanning electron microscope (SEM). Through the XRD, TG and FTIR analysis, the results showed that the addition of $\mathrm{FS}+\mathrm{H}_{3} \mathrm{PO}_{4}+\mathrm{FeSO}_{4} \cdot 7 \mathrm{H}_{2} \mathrm{O}+$ TEOS resulted in the generation of the amorphous phase during the water immersion. This amorphous gel was identified as a mixture of a magnesium-chloride-silicate-hydrate gel ( $M-C l-S-H$ gel) and an insoluble magnesium-chloride-hydrate gel ( $M-C l-H$ gel) by Energy Dispersive Spectrometer (EDS). The generation of the insoluble $\mathrm{M}-\mathrm{Cl}-\mathrm{S}-\mathrm{H}$ gel and $\mathrm{M}-\mathrm{Cl}-\mathrm{H}$ gel and the densification of the microstructure contributed to the valuable and long-term improvement of the water resistance in the MOC. Then the transformation of the morphology might be due to the interaction performance and superposed effect of $\mathrm{FS}, \mathrm{H}_{3} \mathrm{PO}_{4}, \mathrm{FeSO}_{4} \cdot 7 \mathrm{H}_{2} \mathrm{O}$ and TEOS.
\end{abstract}

\section{INTRODUCTION}

Magnesium oxychloride cement (MOC), also known as Sorel cement or magnesia cement, is an air-dried magnesia-based cementing material invented by French scientist Sorel in 1867 . It is a pneumatic cementitious material formed by mixing a certain concentration of a magnesium chloride solution with a light-burned magnesia powder. At room temperature, its hydration products are mainly $5 \mathrm{Mg}(\mathrm{OH})_{2} \cdot \mathrm{MgCl}_{2} \cdot 8 \mathrm{H}_{2} \mathrm{O} \quad(5 \cdot 1 \cdot 8$ phase $)$, $3 \mathrm{Mg}(\mathrm{OH})_{2} \cdot \mathrm{MgCl}_{2} \cdot 8 \mathrm{H}_{2} \mathrm{O}(3 \cdot 1 \cdot 8$ phase $)$ and $\mathrm{Mg}(\mathrm{OH})_{2}$ [1-9]. These hydration products are cross-connected to form a crystal network structure [10]. Compared with ordinary Portland cement (OPC), MOC has many superb properties, such as having early strength, high strength, being light-weight, having a low alkalinity, being a wood substitute and a heat insulator $[11,12]$. These make it a promising material for applications in producing light insulation board, electrical insulating materials and fire-proof materials.

However, a crucial defect of MOC is its poor water resistance. Due to the poor resistance to water, little commercial or industrial attention has been paid to the MOC when compared with the OPC, which has drawn much concern for many years [13, 14]. A previous stu- dy [14] has shown that the compressive strength of the MOC after 28 days water immersion decreases by $90 \%$. The main reason is attributed to the predominant hydration products in the MOC, such as the $5 \cdot 1 \cdot 8$ phase and the $3 \cdot 1 \cdot 8$ phase, which are unstable and gradually decompose to $\mathrm{Mg}(\mathrm{OH})_{2}$ and other soluble ions in water, thus, leading to a significant decrease in the compressive strength [11], as shown in Equation 1 and 2. As a result, if the water resistance of the MOC pastes is improved, this will make it a promising cementing material to be used widely.

$$
\begin{aligned}
& 5 \mathrm{Mg}(\mathrm{OH})_{2} \cdot \mathrm{MgCl}_{2} \cdot 8 \mathrm{H}_{2} \mathrm{O}= \\
& =5 \mathrm{Mg}(\mathrm{OH})_{2}+\mathrm{Mg}^{2+}+2 \mathrm{Cl}^{-}+8 \mathrm{H}_{2} \mathrm{O} \\
& 3 \mathrm{Mg}(\mathrm{OH})_{2} \cdot \mathrm{MgCl}_{2} \cdot 8 \mathrm{H}_{2} \mathrm{O}= \\
& =3 \mathrm{Mg}(\mathrm{OH})_{2}+\mathrm{Mg}^{2+}+2 \mathrm{Cl}^{-}+8 \mathrm{H}_{2} \mathrm{O}
\end{aligned}
$$

Various methods and means have been adopted to improve the water resistance of the MOC. Among them, adding additives and supplementary cementitious materials are the most effective ways $[15,16]$. Researchers have reported that the compressive strength of the MOC decreased by only $10 \%$ and $15 \%$ when adding $1 \%$ soluble phosphates [14] and $30 \%$ fly ash (FS), respectively [11] for a 28-day water immersion. 
Qing H., Ying L., Jing W., Weixin Z., Chenggong Ch., Jinmei D., Danchun A., Xueying X., Yuan Z.

Table 1. The chemical compositions of the raw materials used.

\begin{tabular}{llllccccc}
\hline \multirow{2}{*}{ Light-burnt magnesia } & Components & $\mathrm{MgO}$ & $\mathrm{CaO}$ & $\mathrm{Al}_{2} \mathrm{O}_{3}$ & $\mathrm{SiO}_{2}$ & $\mathrm{Fe}_{2} \mathrm{O}_{3}$ & \multicolumn{2}{c}{ Loss on ignition } \\
& Mass fraction (\%) & 85.96 & 1.29 & 1.28 & 6.03 & 0.57 & 4.87 \\
\hline \multirow{2}{*}{ Bischofite } & Components & $\mathrm{MgCl}_{2}$ & $\mathrm{KCl}$ & $\mathrm{NaCl}$ & $\mathrm{CaCl}_{2}$ & $\mathrm{MgSO}_{4}$ & Water insoluble \\
& Mass fraction (\%) & 46.43 & 0.21 & 0.36 & 0.01 & 0.02 & 0.07 \\
\hline \multirow{2}{*}{ Fly ash } & Components & $\mathrm{SiO}_{2}$ & $\mathrm{Al}_{2} \mathrm{O}_{3}$ & $\mathrm{Fe}_{2} \mathrm{O}_{3}$ & $\mathrm{CaO}$ & $\mathrm{K}_{2} \mathrm{O}$ & Others \\
& Mass fraction (\%) & 55.84 & 29.92 & 5.27 & 5.12 & 1.93 & 19.2 \\
\hline
\end{tabular}

What is more, the literature has reported that ferrous sulfate $\left(\mathrm{FeSO}_{4} \cdot 7 \mathrm{H}_{2} \mathrm{O}\right)$ also has a positive effect on the water resistance of the MOC [15]. However, the strength retention of the MOC is still reduced (less than $100 \%$ ) by the addition of the soluble phosphates, FS and $\mathrm{FeSO}_{4} \cdot 7 \mathrm{H}_{2} \mathrm{O}$ after the 28-day water immersion. Meanwhile, the long-term strength retention of the MOC is much lower than $100 \%$ and a few literature articles have been reported for the long-term water resistance. Consequently, it is urgent to find more effective additives to further improve the long-term water resistance of the MOC.

Compounds containing $\mathrm{Si}-\mathrm{C}$ bonds are commonly referred to as organosilicon compounds. Due to the combination of the inorganic and organic materials, silicone has the advantages of high and low temperature resistance, electrical insulation, ozone resistance, radiation resistance, flame retardancy, water repellency, corrosion resistance, non-toxicity, being odourless and having physiological inertness [16]. It has reported that silicone polymers can cross-link with the hydration products in the magnesium oxychloride cementitious materials that can improve the water resistance of the MOC [16]. There are two possible reasons [15]: one, the silicone polymers can fill the capillary channels, thus, they inhibit the free movement of water molecules in the cementitious materials. The other is the formation of a hydrophobic protective layer on the surface of the crystals of the hydration products. Among the organosilicon compounds, ethyl silicate (TEOS) is the most widely used raw material for the preparation of silicone resin materials [16].

In order to further improve the water resistance of the MOC, ethyl silicate was introduced to be added into the $\mathrm{FS}, \mathrm{H}_{3} \mathrm{PO}_{4}$ and $\mathrm{FeSO}_{4} \cdot 7 \mathrm{H}_{2} \mathrm{O}$ MOC cement in this experiment. Then the effect of the $\mathrm{FS}, \mathrm{H}_{3} \mathrm{PO}_{4}$, $\mathrm{FeSO}_{4} \cdot 7 \mathrm{H}_{2} \mathrm{O}$ and TEOS on the water resistance was studied in detail through the strength retention coefficient, the TG/DTG curves, the infrared spectrum, the phase composition and the micromorphology.

\section{EXPERIMENTAL}

\section{Raw materials}

The magnesium oxide used in this experiment was a yellowish light-burned magnesia powder (Haicheng, Liaoning, China), which was obtained by calcination magnesite at approximately $750{ }^{\circ} \mathrm{C}$. It was tested by the direct hydration method [17] with an active content of $55.4 \%$. The bischofite employed was a hygroscopic hexa-hydrate crystal $\left(\mathrm{MgCl}_{2} \cdot 6 \mathrm{H}_{2} \mathrm{O}\right)$ with a purity of 98 \% from Jiayoumeiye Ltd, Qinghai Province, China. The additives used in this experiment containing the aggregate and the modifiers were FS and $\mathrm{H}_{3} \mathrm{PO}_{4}$, $\mathrm{FeSO}_{4} \cdot 7 \mathrm{H}_{2} \mathrm{O}$, TEOS, which were produced from a local power plant, and Sinopharm Group, respectively. The chemical composition of the light-burnt magnesia, bischofite and fly ash were determined by an X-ray fluorescence spectrometer (XRF, Axios PW4400), and are summarised in Table 1.

\section{Specimen preparation}

The molar ratio of the active $\mathrm{MgO} / \mathrm{MgCl}_{2} / \mathrm{H}_{2} \mathrm{O}$ of MOC cement preparation was $7: 1: 15$, which is the same as the previous reference $[18,19]$. To prepare the neat MOC specimens, bischofite was firstly dissolved into the water before mixing it with the light-burned magnesia. Secondly, the prepared fresh slurry with the $30 \% \mathrm{FS}, 1 \% \mathrm{H}_{3} \mathrm{PO}_{4}$ and $3 \% \mathrm{FeSO}_{4} \cdot 7 \mathrm{H}_{2} \mathrm{O}$ additives by the light-burnt magnesia powder weight were cast in steel moulds with a size of $20 \times 20 \times 20 \mathrm{~mm}$ through vibration compaction. Based on the above incorporation of the additives, the ethyl silicate was further added with a percentage of $0.1 \%, 0.3 \%, 0.5 \%, 0.7 \%, 0.9 \%, 1.2 \%$ and $1.5 \%$, respectively. For convenience, the samples were labelled T1, T3, T5, T7, T9, T12, T15, respectively, and $\mathrm{T} 0$ represents the neat $\mathrm{MOC}$ with no additives. The prepared fresh samples were covered with plastic sheets to avoid evaporation and were initially air cured for $24 \mathrm{~h}$ at room temperature. The specimens were then removed from the moulds and cured in an air environment for 28 days.

\section{Specimen analysis}

The unconfined compressive strength of the samples was tested using a testing machine (MTS, SANYU, SYE-3000B) using a maximum force of $300 \mathrm{kN}$ at a loading rate of $1.52 \mathrm{~mm} \cdot \mathrm{min}^{-1}$, three samples were tested for each composition and age. The crushed cement was reduced through an 80um sieve for the crystal phase composition analysis by XRD patterns, which were collected on an X' Pert Pro (PANalytical) diffractometer with $\mathrm{CuK} \alpha$ radiation $(\gamma=0.15419 \mathrm{~nm})$ over a $2 \theta$ range 
from $5^{\circ}$ to $70^{\circ}$. The microstructures of the MOC specimens cured in the air environment for 28 days and further immersing were characterised by scanning electron microscopy (SEM, JSM-5610LV) on the fractured surfaces after gold coating. A thermos Scientific Nicolet spectrometer was used for the Fourier-transformed infrared spectroscopy (FTIR). The spectral analysis was performed in the range of $4000-400 \mathrm{~cm}^{-1}$, with a spectral resolution of $1 \mathrm{~cm}^{-1}$. The thermogravimetric curves were recorded with a differential scanning calorimetry (TG-DSC, NETZSCH SAT 200F3). The samples were heated from room temperature to $800{ }^{\circ} \mathrm{C}$ under the protection of a nitrogen atmosphere at a heating rate of $10^{\circ} \mathrm{C} \cdot \mathrm{min}^{-1}$.

To evaluate the water resistance of the MOC, the specimens cured for 28 days in the air environment were dipped in water at $20 \pm 3{ }^{\circ} \mathrm{C}$, and the compressive strength of the samples after the different immersion times in the water was measured and used to calculate the strength retention coefficient $\left(\mathrm{R}_{\mathrm{f}) \text { as follows }}[18,19]\right.$ :

$$
R_{f}=R(W, n) / R(A, 28)
$$

where $R(W, n)$ and $R(A, 28)$ denote the compressive strength of the specimens after immersion in the water for $\mathrm{n}$ days and the compressive strength of the specimens cured in the air environment for 28 days, respectively.

\section{RESULTS AND DISCUSSION}

Compressive strength

As a potential building material, the compressive strength is one of the key parameters to evaluate the properties of the MOC. The compressive strength development of the MOC at the different curing times is shown in Figure 1. From Figure 1, we can clearly see that the controlled sample has a much higher compressive strength than those of the blended paste at all the tested ages. There are two possible reasons for that: (1) the

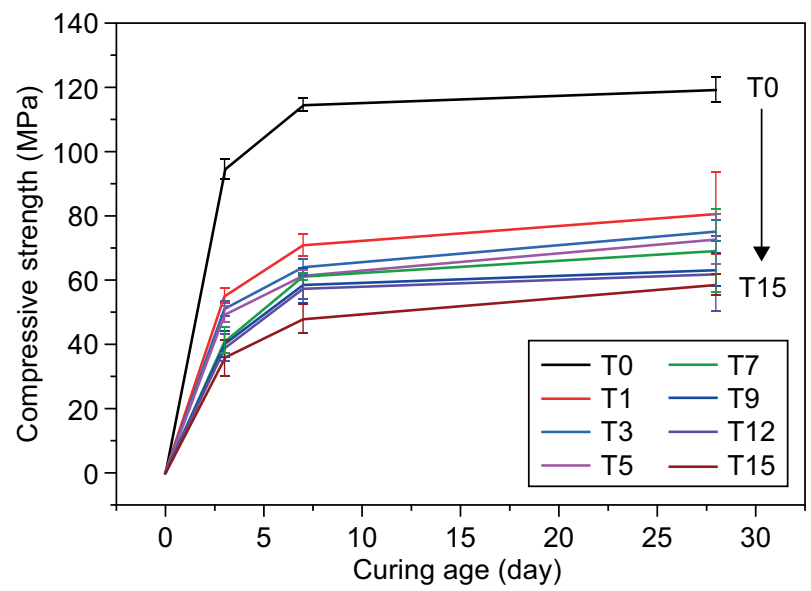

Figure 1. The compressive strength development of the MOC pastes after air curing (The error bar represents the standard deviation). replacement of the $\mathrm{MgO}$ decreases the quantity of the main hydration product, especially for the addition of the FS; (2) the higher water absorption of the $\mathrm{H}_{3} \mathrm{PO}_{4}$, $\mathrm{FeSO}_{4} \cdot 7 \mathrm{H}_{2} \mathrm{O}$ and TEOS allows less water to be available for the hydration, thus, it retards the crystal growth in the MOC pastes. The compressive strength of the blended paste decreases with the increase in the replacement ratio of the TEOS, which is similar with the previous results [11]. Other researchers have also found that additives reduce the strength of the MOC before 28 days [15]. For instance, the compressive strength of T0, T1, T9 and T15 are 119.2 $\mathrm{MPa}, 80.7 \mathrm{MPa}, 63.2 \mathrm{MPa}$ and $58.6 \mathrm{MPa}$ at 28 days of air curing, respectively. It should not to be neglected that T9 and T15 are $47.0 \%$ and $50.8 \%$ lower than the controlled sample, respectively. However, the compressive strength of all the samples are higher than $50 \mathrm{MPa}$ at 28 days of air curing, which satisfies the requirement of the engineering application.

\section{Strength retention coefficient}

The compressive strength retention coefficient of the MOC pastes after immersion in the water for 28 days, 56 days and 210 days are plotted in Figure 2. In Figure 2, we can clearly see that the strength retention coefficients of the blended MOC samples are all higher than $100 \%$ after the 28-day water immersion. After further immersion in water for 56 days, the strength retention coefficients of the MOC pastes reduce with a different degree. Except for T9 and T12, the strength retention coefficients of all the other pastes are lower than $100 \%$. While, it is worth noting that the strength retention coefficient of $\mathrm{T} 9$ is higher than the other samples and higher than $100 \%$ before the 56 days of water immersion. Then, after the further immersion in the water for 210 days, the strength retention coefficients of the MOC are all lower than $100 \%$. Nevertheless, the T9 sample also has the highest strength retention coefficient when compared to the other samples, as shown in Figure 2. Meanwhile, the strength retention coefficient almost maintains about $80 \%$ after the 210 -day water immersion. But, the neat controlled MOC cement has the lowest strength retention coefficient with $14.7 \%$, $12.3 \%$ and $8.01 \%$ at the 28-day, 56-day and 210-day immersion. Therefore, the results demonstrate that $\mathrm{T} 9$ exhibits best water resistance over the other pastes. This indicates that the addition of $0.9 \%$ TEOS is the optimum mix ratio in the MOC which is beneficial for the water resistance in this experiment. This also indicates that the addition of $\mathrm{FS}+\mathrm{H}_{3} \mathrm{PO}_{4}+\mathrm{FeSO}_{4} \cdot 7 \mathrm{H}_{2} \mathrm{O}+$ TEOS is an effective method for the MOC to obtain brilliant water resistance. The above noticeable results may be due to the water environment that provides sufficient free water that facilitates the secondary hydration of the MOC pastes that form more main crystal phases after the water immersion, as reported in the previous literature $[20,21]$. It has been reported in the literature 
Qing H., Ying L., Jing W., Weixin Z., Chenggong Ch., Jinmei D., Danchun A., Xueying X., Yuan Z.

[22] that the improvement of the water resistance in the MOC mortars with the FS incorporation may be attributed to the amorphous aluminosilicate gel formed by the pozzolanic reaction of the reactive $\mathrm{SiO}_{2}$ and $\mathrm{Al}_{2} \mathrm{O}_{3}$ contents under the alkaline condition of the MOC system. With a large surface area, the well dispersed FS particles can form a network of the aluminosilicate gel weaved with the microstructure of the MOC crystals. As a result, the water shy MOC phases can be protected to a certain extent by the surrounding spherical FS particles and water insoluble aluminosilicate gel, thus, inhibits the growth of brucite in the MOC matrix by the addition of FS [22]. Besides, it has been reported that sulfate ions can block the hydration of $\mathrm{MgO}$ and the formation of $\mathrm{Mg}(\mathrm{OH})_{2}$ resulting in a good volume stability in a humid environment and a smaller amount of hydration products in the MOC [15]. Additionally, there are two probable reasons for the addition of $\mathrm{H}_{3} \mathrm{PO}_{4}$ which increases the stability of the main hydration phases in the water. The first is the phosphate radical anions decrease the lowest concentration of the $\mathrm{Mg}^{2+}$ ions required for the formation and the stable existence of the $5 \cdot 1 \cdot 8$ phase [14]. The other may be that the $\mathrm{H}_{3} \mathrm{PO}_{4}$ can react with the $5 \cdot 1 \cdot 8$ phase which forms the insoluble magnesium phosphate hydrates $\left(\mathrm{Mg}_{3}\left(\mathrm{PO}_{4}\right)_{2} \cdot 8 \mathrm{H}_{2} \mathrm{O}\right)$ and the $\left(\mathrm{Mg}_{3}\left(\mathrm{PO}_{4}\right)_{2} \cdot 10 \mathrm{H}_{2} \mathrm{O}\right)$ outside the surface of the cement [23]. What is more, the researcher [16] has found that the incorporation of the TEOS can undergo a poly-condensation reaction, be cross-linked with the hydration product and it fills the pores in the MOC. The capillary channel prevents the water molecules from moving freely inside the gelled material structure, and forms a hydrophobic protective layer on the surface of the inorganic material or the hydrated product crystal. However, the main reasons for the MOC incorporation of FS $+\mathrm{H}_{3} \mathrm{PO}_{4}+\mathrm{FeSO}_{4} \cdot 7 \mathrm{H}_{2} \mathrm{O}+$ + TEOS with excellent water resistance are unintelligible. This will be discussed in next sections.

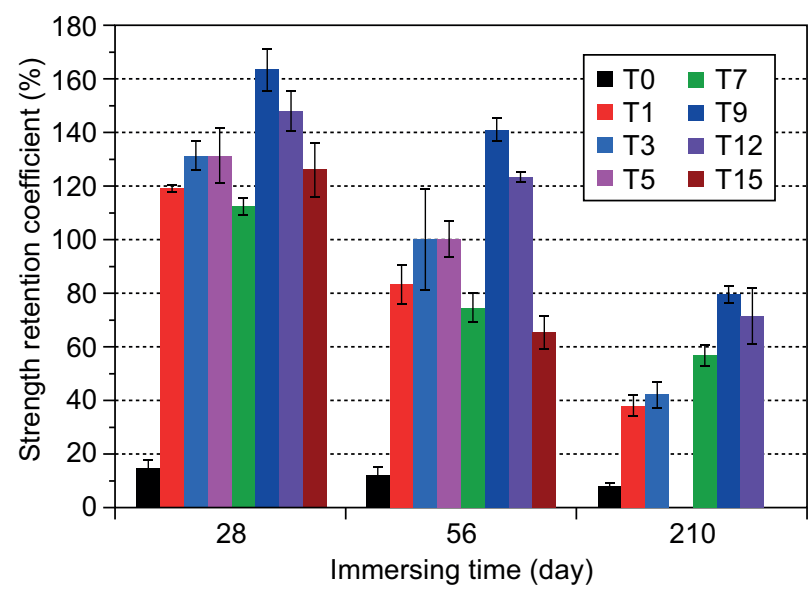

Figure 2. The strength retention coefficient of the MOC pastes after the immersion (The error bar represents the standard deviation).
XRD analysis

The XRD diffraction patterns of the MOC paste after the 28-day air curing are presented in Figure 3. It can be seen that the main crystallised hydration product of the MOC paste is the $5 \cdot 1 \cdot 8$ phase, irrespective of whether the additives are added. It is well known that the $5 \cdot 1.8$ phase is the most important crystal phase which affects the mechanical strength in the $\operatorname{MOC}[2,11]$. The peak areas of $5 \cdot 1 \cdot 8$ phase in the MOC with and without the additives are evidently different. The peak area of the neat MOC is much higher than the modified MOC. However, the peak areas of the unreacted magnesia in the MOC with and without the additives are very similar apart from the T9 sample. The XRD patterns may verify the addition of the FS replaced the amount of the $\mathrm{MgO}$ that decreases the quantity of the main hydration product. Meanwhile, incorporation of the $\mathrm{H}_{3} \mathrm{PO}_{4}, \mathrm{FeSO}_{4} \cdot 7 \mathrm{H}_{2} \mathrm{O}$ and TEOS absorb the available water for the hydration that retards the crystal growth in the MOC pastes. It is worth noting that the percentage of the $5 \cdot 1 \cdot 8$ phase decreases after increasing the percentage of the TEOS from the XRD pattern peaks, which indicate a decrease in the compressive strength in the MOC after the increase of the TEOS percentage at the 28-day air curing. It is crystal clear that there a peak of brucite exists which means there is excessive magnesia in the MOC after the hydration. Obviously, the big difference between the T9 sample and the controlled sample is the percentage of the non-reacted magnesia, which can be seen from Figure $3 \mathrm{c}$. The T9 sample has the lowest percentage of magnesia over the other samples. Nevertheless, the peak areas of the $5 \cdot 1 \cdot 8$ phase and the brucite are not significantly increased as shown in Figure $3 \mathrm{~b}$. This phenomenon may be attributed to the proper content of the TEOS coating on the surface of the magnesia that prevents the magnesia from forming brucite and avoiding detection by the XRD to some extent.

The characteristic peaks of the MOC after the 56-day immersion in the water are exhibited in Figure 4. It can be found that the XRD pattern of the controlled sample is a brucite peak and there are definitely not any $5 \cdot 1 \cdot 8$ phase peaks that exist anymore. This demonstrates the low compressive strength retention coefficient for T0. In comparison with the air curing, all the $5 \cdot 1 \cdot 8$ phase peaks in the MOC are lower after the water immersion for the 56-day and the T9 sample is without exception. Besides, T9 has a higher percentage of brucite and a lower percentage of the $5 \cdot 1 \cdot 8$ phase than the MOC incorporation of the different percentage of the TEOS. However, the interval graph of the magnesia after the water immersion is similar to the 28-day air curing interval graph (Fig. $3 \mathrm{c}$ ). The above results are in contradiction with the highest strength retention of the T9 samples. What is more, the content of the brucite is not significantly increased after the 56-day water immersion for the MOC after the addition of the $\mathrm{FS}+\mathrm{H}_{3} \mathrm{PO}_{4}+$ 


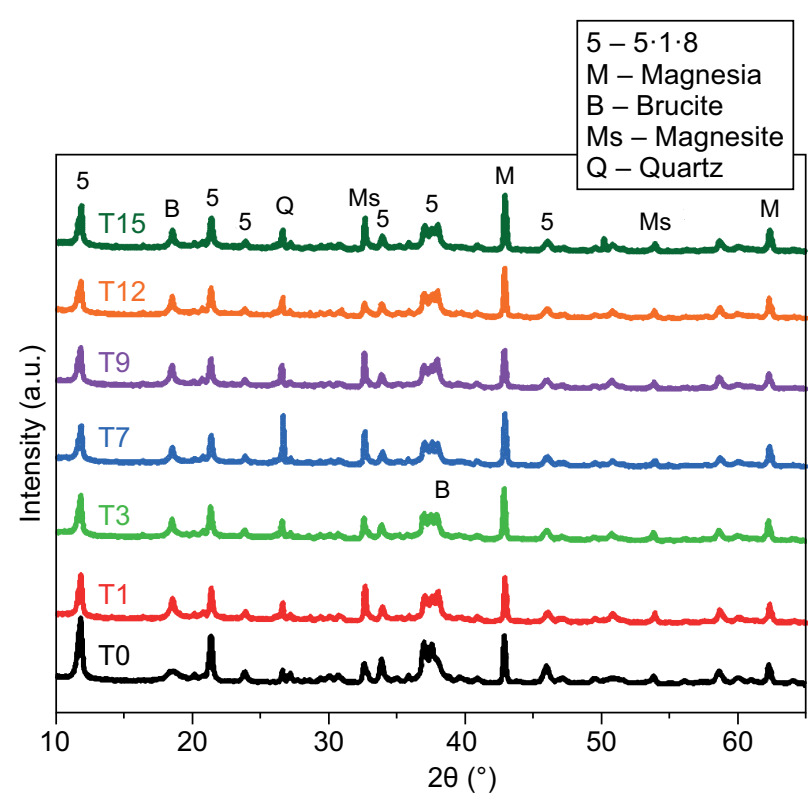

a)

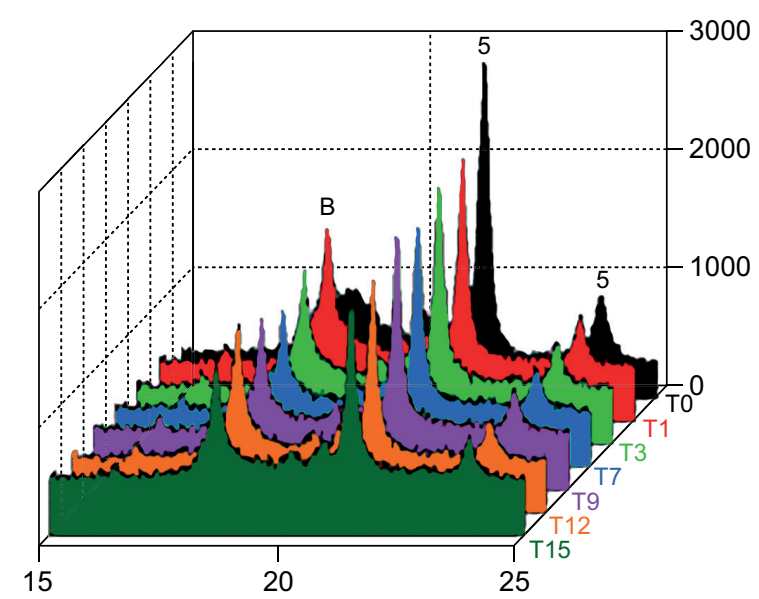

b)

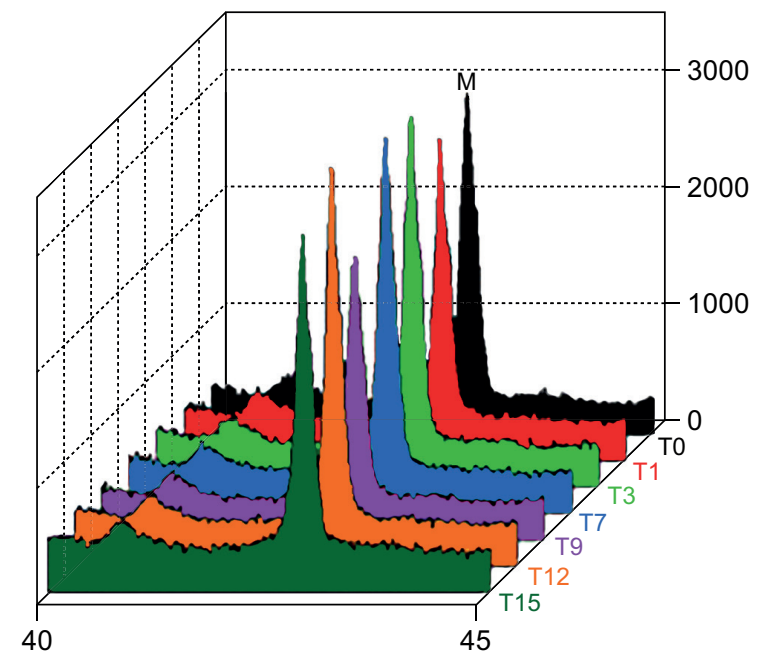

c)

Figure 3. The XRD patterns (a) and the interval graphs (b, c) of the MOC pastes after the 28-day air curing.

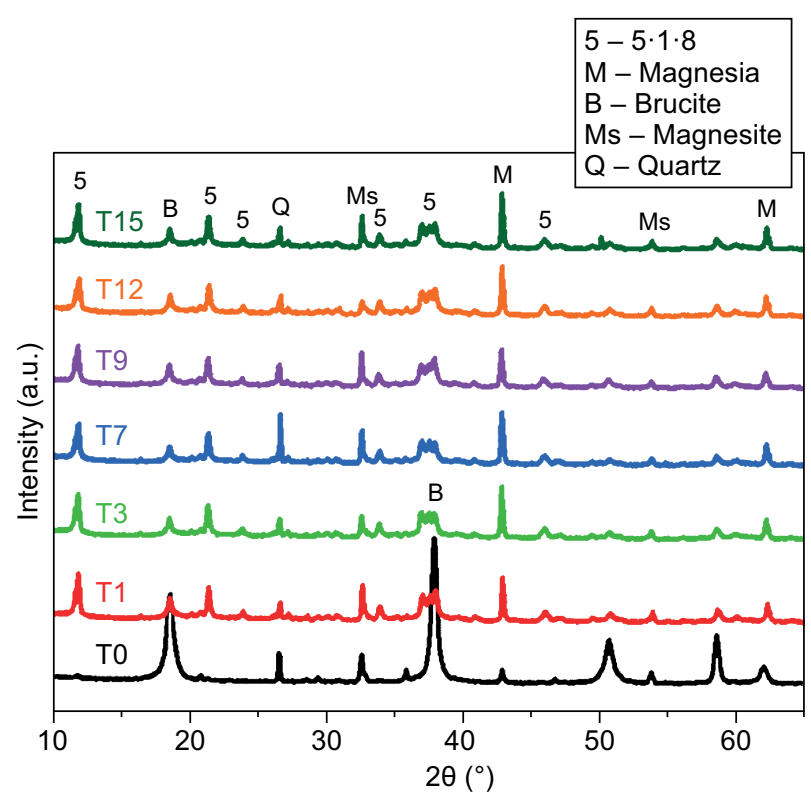

a)

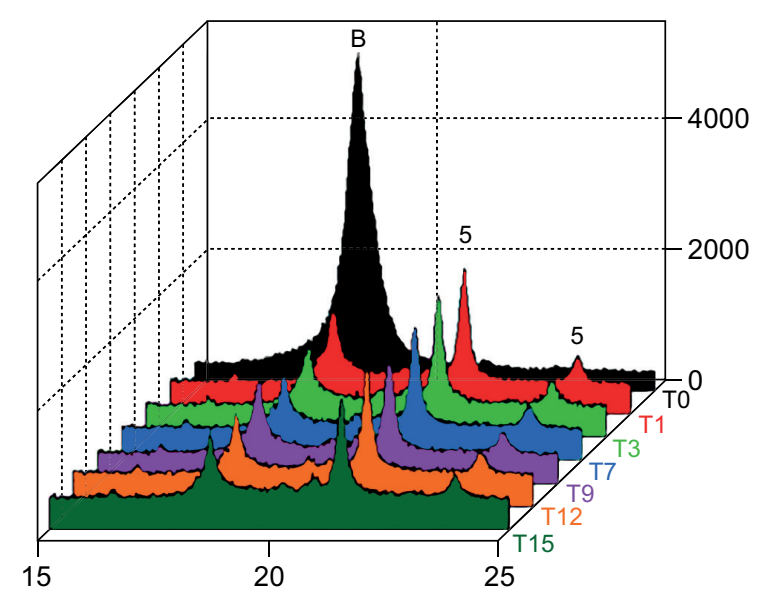

b)

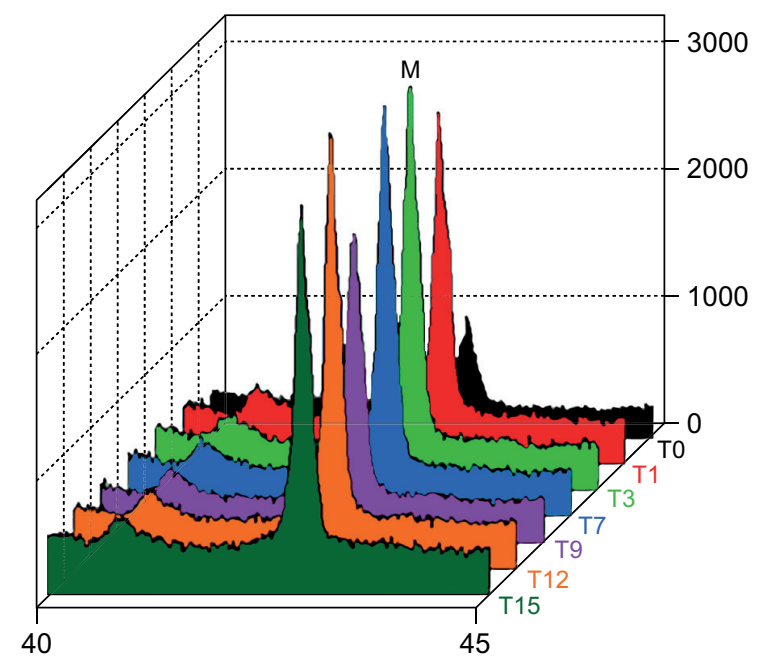

c)

Figure 4. The XRD patterns (a) and the interval graphs (b, c) of the MOC pastes after 56-day immersion. 
Qing H., Ying L., Jing W., Weixin Z., Chenggong Ch., Jinmei D., Danchun A., Xueying X., Yuan Z.

$+\mathrm{FeSO}_{4} \cdot 7 \mathrm{H}_{2} \mathrm{O}+$ TEOS. These results demonstrate there is no significant secondary hydration process that happens when incorporating the additives. Then, the decreased content of the $5 \cdot 1 \cdot 8$ phase after the water immersion may be due to the transformation of the crystal phases to the amorphous phases that cannot be detected by the XRD patterns.

TG

The TG/DTG analysis of MOC with and without the additives is given in Figure 5. There are four processes of dehydration and decomposition in the thermographs of the MOC and is shown as follows [20, 21, 24]:

$$
\begin{aligned}
& 5 \mathrm{Mg}(\mathrm{OH})_{2} \cdot \mathrm{MgCl}_{2} \cdot 8 \mathrm{H}_{2} \mathrm{O} \rightarrow \\
& \rightarrow 5 \mathrm{Mg}(\mathrm{OH})_{2} \cdot \mathrm{MgCl}_{2} \cdot 4 \mathrm{H}_{2} \mathrm{O}+4 \mathrm{H}_{2} \mathrm{O}
\end{aligned}
$$

$5 \mathrm{Mg}(\mathrm{OH})_{2} \cdot \mathrm{MgCl}_{2} \cdot 4 \mathrm{H}_{2} \mathrm{O} \rightarrow$ $\rightarrow 5 \mathrm{Mg}(\mathrm{OH})_{2} \cdot \mathrm{MgCl}_{2}+4 \mathrm{H}_{2} \mathrm{O}$

$\left(140-200{ }^{\circ} \mathrm{C}\right)$

$5 \mathrm{Mg}(\mathrm{OH})_{2} \cdot \mathrm{MgCl}_{2} \rightarrow$

$\rightarrow \mathrm{MgCl}_{2} \cdot \mathrm{H}_{2} \mathrm{O}+\mathrm{MgO}$

$\left(200-350{ }^{\circ} \mathrm{C}\right)$

$\mathrm{MgCl}_{2} \cdot \mathrm{H}_{2} \mathrm{O} \rightarrow \mathrm{MgO}+2 \mathrm{HCl}$

$\left(350-450{ }^{\circ} \mathrm{C}\right)$

$\mathrm{MgCO}_{3} \rightarrow \mathrm{MgO}+\mathrm{CO}_{2}$

$\left(450-600^{\circ} \mathrm{C}\right)$

Both the mass loss between $350{ }^{\circ} \mathrm{C}$ and $500{ }^{\circ} \mathrm{C}$ in T0 and T9 after 28 days of air curing are about $9.0 \%$, but the water of the crystallisation in $\mathrm{T} 0$ was higher than that of T9 as shown in Table 2. This suggests that the amount of the water of the crystallisation associated with the additives was less than that of T0. This also indicates that new amorphous phases are produced when adding the FS $+\mathrm{H}_{3} \mathrm{PO}_{4}+\mathrm{FeSO}_{4} \cdot 7 \mathrm{H}_{2} \mathrm{O}+$ TEOS. Meanwhile, the amount of the water of the crystallization in these amorphous phases was less than that of the $5 \cdot 1 \cdot 8$ phase.

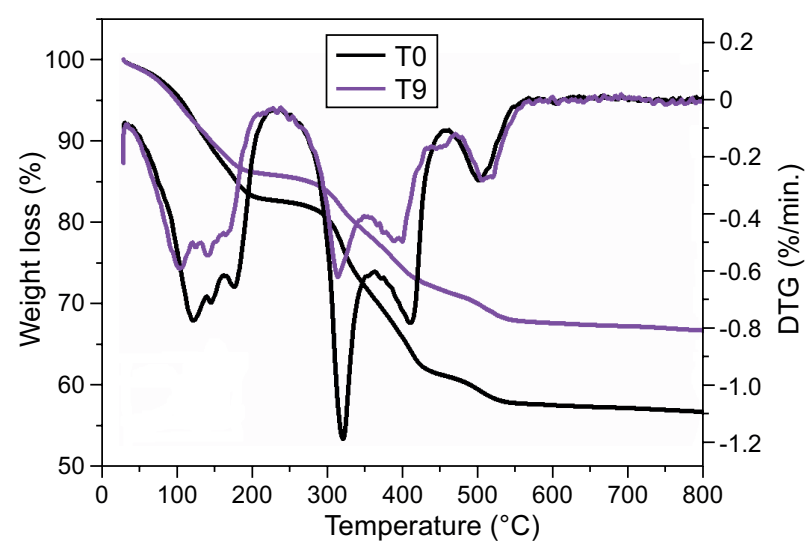

Figure 5. The TG/DTG curves of the MOC after 28 days of air curing.
Table 2. The mass loss in the MOC (\%).

\begin{tabular}{lcrr}
\hline Temperature & Element & \multicolumn{1}{c}{ T0 } & \multicolumn{1}{c}{ T9 } \\
\hline $60-200^{\circ} \mathrm{C}$ & $\mathrm{H}_{2} \mathrm{O}$ & 17.36 & 14.23 \\
$200-350^{\circ} \mathrm{C}$ & $\mathrm{OH}$ & 12.29 & 9.56 \\
$350-450^{\circ} \mathrm{C}$ & $\mathrm{HCl}$ & 9.11 & 8.97 \\
$450-600^{\circ} \mathrm{C}$ & $\mathrm{CO}_{2}$ & 4.86 & 4.68 \\
\hline
\end{tabular}

\section{IR spectrum}

The FTIR spectrum of the original TEOS as well as the MOC blended with the TEOS are shown in Figure 6. The TEOS spectrum shows two peaks at $2976.3 \mathrm{~cm}^{-1}$ and $2920.6 \mathrm{~cm}^{-1}$, which are the characteristics of the $\mathrm{C}-\mathrm{H}$ stretching vibrations [25]. The absorption peaks at $954.9 \mathrm{~cm}^{-1} \& 1075.7 \mathrm{~cm}^{-1}$ are the characteristics of the $\mathrm{Si}-\mathrm{O}-\mathrm{Si}$ vibrations. The characteristic absorption peaks of $\mathrm{Si}-\mathrm{CH}_{3}$ are at $779.6 \mathrm{~cm}^{-1}$ and $1386.9 \mathrm{~cm}^{-1}$. The absorption peak of $1442.7 \mathrm{~cm}^{-1}$ belongs to the vibration of $\mathrm{Si}-\mathrm{O}$. These results are consistent with the standard spectra of the TEOS. From the enlarged picture in Figure $6 \mathrm{~b}$, there is a very weak absorption peak at $1386.9 \mathrm{~cm}^{-1}$ in T9. This is the absorption peak that was formed by the bonding of the TEOS with the MOC [16]. This proves that the chemical cross-linking reaction happens between the TEOS and the MOC through the hydrolysis condensation of the TEOS [16]. When compared to the neat MOC with two sharp peaks, T9 cured in the air environment for 28 days and immersed in the water for 56 days has a broad band at $1000-1100 \mathrm{~cm}^{-1}$. This characteristic absorption peak demonstrates the existence of the $\mathrm{Si}-\mathrm{O}-\mathrm{Si}$ and $\mathrm{P}-\mathrm{O}$ bands in the MOC for the addition of $\mathrm{FS}$ and $\mathrm{H}_{3} \mathrm{PO}_{4}$. This probably results from the reaction among the $\mathrm{FS}, \mathrm{H}_{3} \mathrm{PO}_{4}$ and the MOC. The series of the bands in the $3600-3800 \mathrm{~cm}^{-1}$ range are the characteristics of the stretching modes of the water molecules [11]. The band at $3700 \mathrm{~cm}^{-1}$ shifts to a lower frequency and almost disappears after blending with $\mathrm{FS}+\mathrm{H}_{3} \mathrm{PO}_{4}+\mathrm{FeSO}_{4} \cdot 7 \mathrm{H}_{2} \mathrm{O}+\mathrm{TEOS}$, indicating the change in the water molecular structure due to the trans-

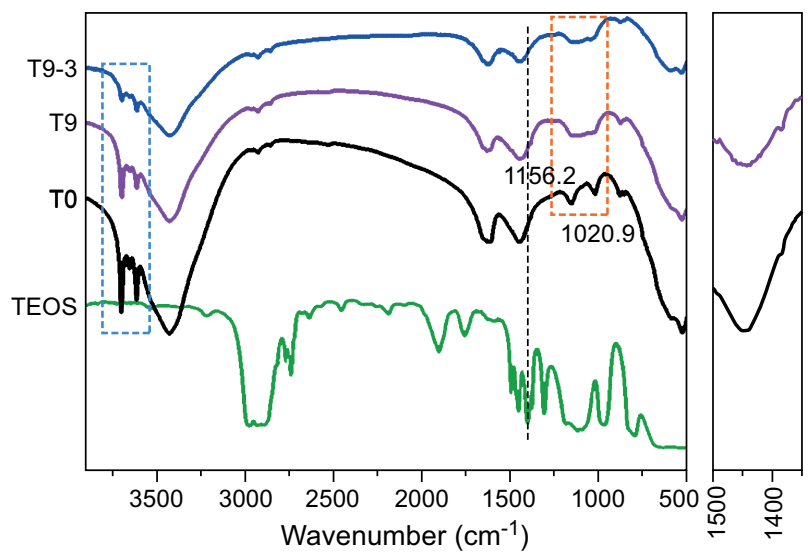

Figure 6. The FTIR spectrum of the MOC pastes (on right is the interval graph). 
formation of the crystalline $5 \cdot 1 \cdot 8$ phase to the amorphous gel in the MOC and the formation of an amorphous gel in T9. What is more, it is interesting to find that more amorphous gels form there after immersion in the water for the 56 days in comparison to without the water immersion MOC, as shown in Figure 6a.

\section{SEM images}

The typical morphology of the hardened MOC paste magnified 100 times is shown in Figure 7. In air curing for 28 days, the T9 sample is more compact than the controlled sample, as shown in Figure $7 \mathrm{a}$ and d. However, spherical and granular substances in the surface of T9 can be clearly seen (Figure 7a), which indicate the existence of a vitreous FS and the unreacted magnesia. Therefore, although T9 has a more compact surface, it has a lower compressive strength than the controlled sample. It is apparent that the controlled sample becomes a loose and porous structure after the water immersion, thus, leading to the low compressive strength and the low strength retention coefficient. On the contrary, the substrate of T9 is denser than the controlled sample after the 28-day water immersion. Simultaneously, the spherical and granular substances disappear completely and have a similar morphology for T9 after the water immersion as the controlled sample cured in the air environment. This demonstrates that the sufficiently provided water and the $\mathrm{H}_{3} \mathrm{PO}_{4}+\mathrm{FeSO}_{4} \cdot 7 \mathrm{H}_{2} \mathrm{O}+$ TEOS interact with the MOC which softened the vitreous FS to form gel substances that cannot be detected by the XRD.
The morphology of the magnified images of the MOC pastes is revealed in Figure 8. From Figure 8a and $8 \mathrm{~d}$, we can clearly find that the substrate of the controlled neat MOC sample is covered with gel-like crystals on the surface and needle-like crystals in the pores. While, the surface of $\mathrm{T} 9$ is completely overlapped with the needle-like crystals in the air curing. The completely covered needle-like crystals may be due to the addition of $\mathrm{H}_{3} \mathrm{PO}_{4}$ that plays an important role in the air cured MOC [23]. This big difference in the microstructure may contribute to the definitely different behaviour after the water immersion. Then, after the water immersion, the controlled sample is blanketed with a flocculent crystal that the Energy Dispersive Spectrometer (EDS) identifies as $\mathrm{Mg}(\mathrm{OH})_{2}$. It is noteworthy that the microstructure of $\mathrm{T} 9$ changes greatly after the water immersion from all needle-like crystals to all gel-like crystals including in the pores, as shown in Figure 6b,c. It has been reported that the amount of the gel-like $5 \cdot 1 \cdot 8$ phase may affect the water resistance of the MOC [15]. The more gel-like the $5 \cdot 1 \cdot 8$ phase has, the better the water resistance of the MOC is. Then, the transformation of the needle-like crystal to the gel-like crystal contributes to the outstanding water resistance of T9. The transformation of the needle-like crystal may be due to the TEOS that hydrolyses in the water which provides more silica. Besides, the incorporation of $\mathrm{H}_{3} \mathrm{PO}_{4}$ and $\mathrm{FeSO}_{4} \cdot 7 \mathrm{H}_{2} \mathrm{O}$ help to accelerate the hydrolysis of the TEOS, thus, producing more and more silica. The produced silica can react with the softened FS to form not only an insoluble magnesium-chloride-hydra-

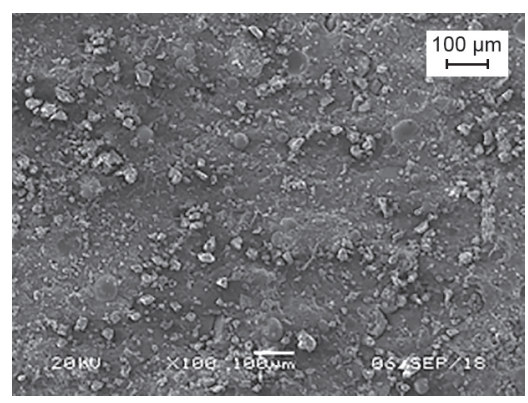

a) T9 A-28

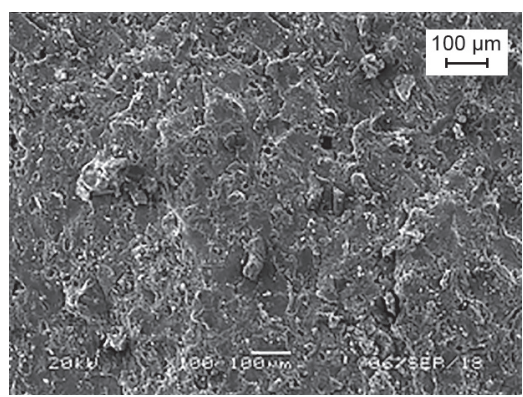

d) T0 A-28

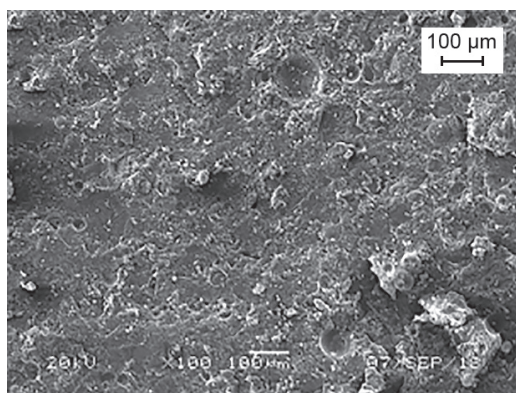

b) $\mathrm{T} 9 \mathrm{~W}-28$

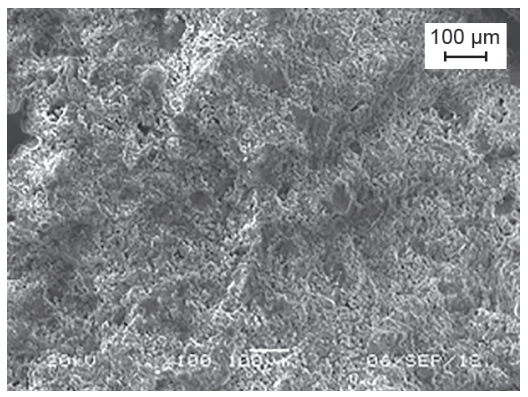

e) T0 W-28

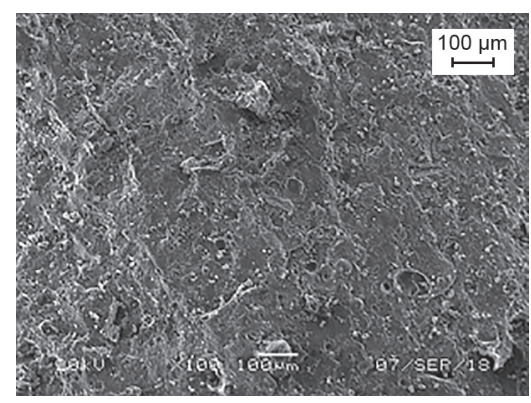

c) T9 W-56

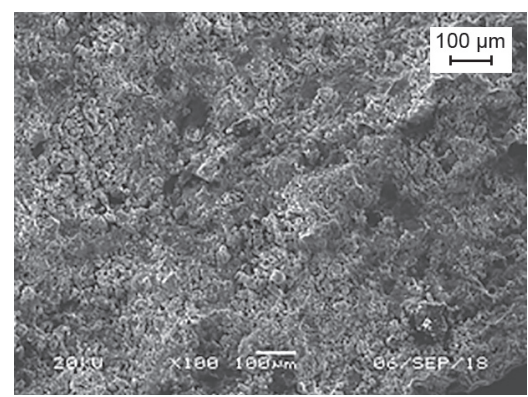

f) T0 W-56

Figure 7. The SEM images of the MOC pastes after the immersion and air curing magnified 100 times (TX A-28: TX cured in the air environment for 28 days; TX W-Y: TX immersion in the water for the Y-day.). 


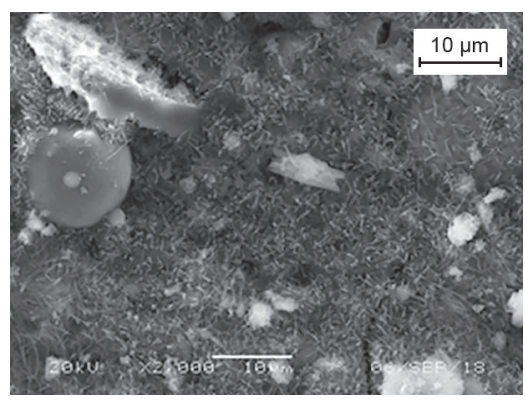

a) T9 A-28

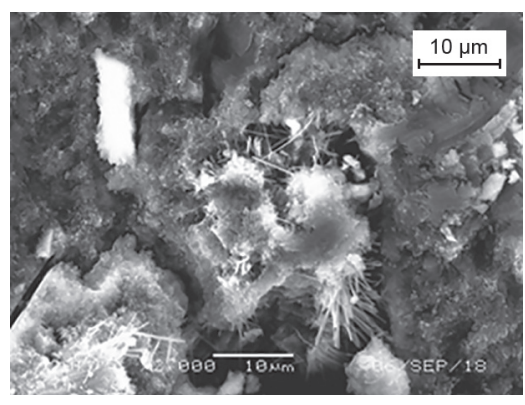

d) T0 A-28

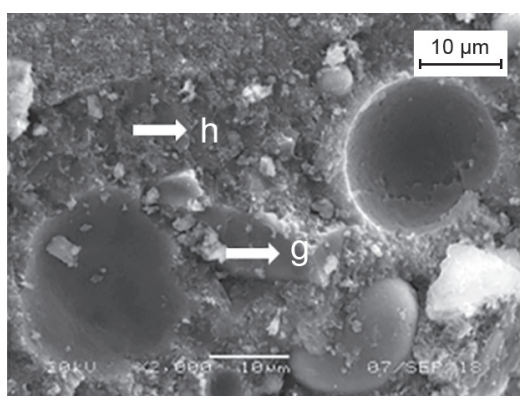

b) T9 W-28

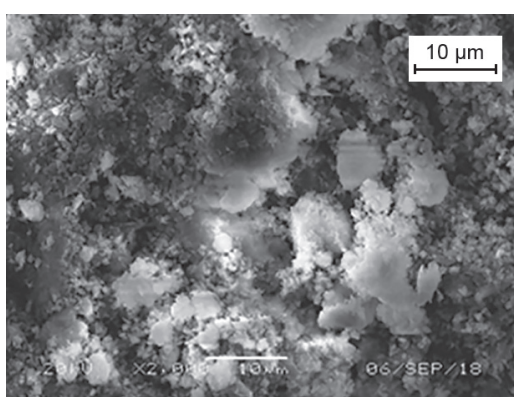

e) T0 W-28

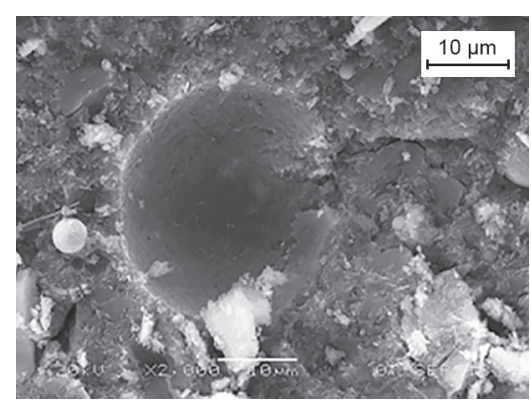

c) T9 W-56

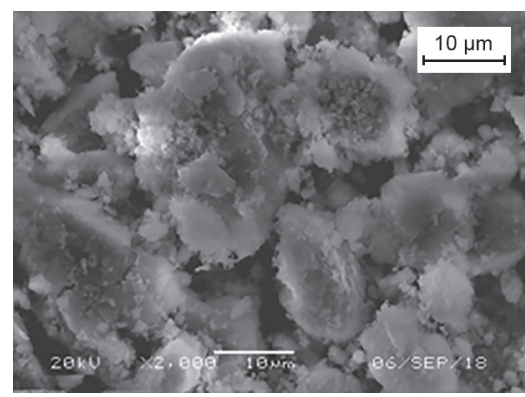

f) T0 W-56
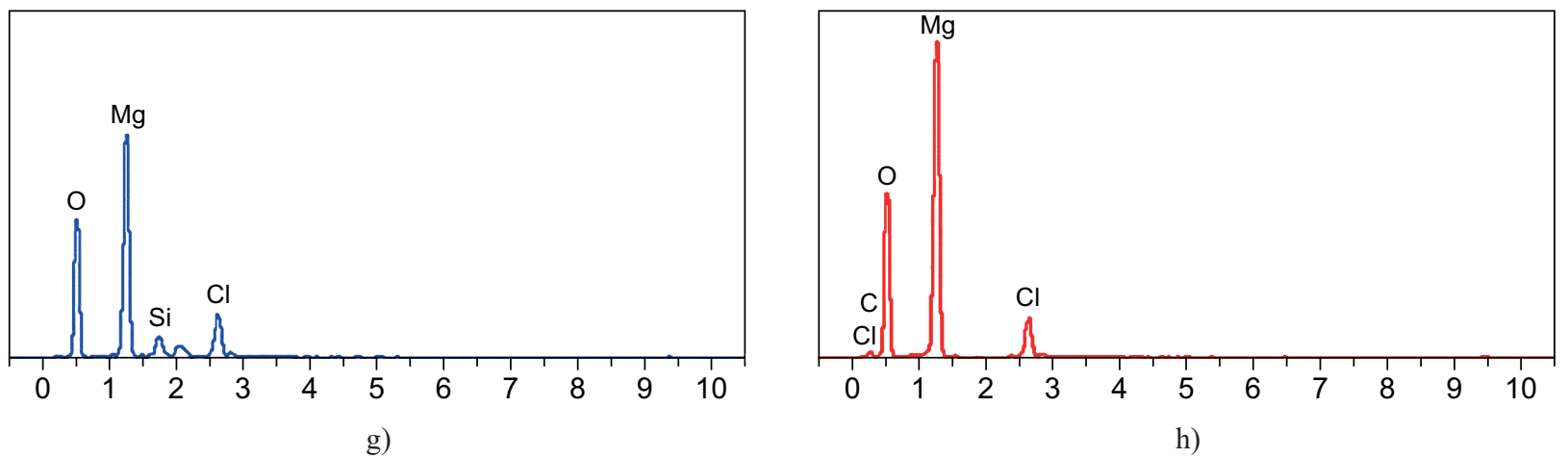

h)

Figure 8. The SEM images of the MOC pastes after the immersion and air curing magnified 2000 times (TX A-28: TX cured in the air environment for 28 days; TX W-Y: TX immersion in the water for the Y-day.).

te gel (M-Cl-H gel) but also an insoluble magnesiumchloride-silicate-hydrate gel (M-Cl-S-H gel), as shown in Figure $8 \mathrm{~g}$ and $\mathrm{h}$. Meanwhile, the water shy MOC phases can be protected by the surrounding spherical FS particles and the water insoluble $\mathrm{M}-\mathrm{Cl}-\mathrm{S}-\mathrm{H}$ gel and the $\mathrm{M}-\mathrm{Cl}-\mathrm{H}$ gel, thus, inhibit the growth of the brucite in the MOC matrix. As a consequence, this means that T9 has the best resistance to water. Thus, it is an effective method to add $\mathrm{FS}+\mathrm{H}_{3} \mathrm{PO}_{4}+\mathrm{FeSO}_{4} \cdot 7 \mathrm{H}_{2} \mathrm{O}+\mathrm{TEOS}$ to improve the water resistance of the MOC.

\section{CONCLUSION}

In this study, the effect of fly ash + phosphoric acid + ferrous sulfate + ethyl silicate on the water resistance of the MOC was investigated. The findings obtained from this study are summarised as follows:

- For the fly ash + phosphoric acid + ferrous sulfate blended paste, with a further addition of $0.9 \%$ ethyl silicate, the water resistance was significantly improved and the strength retention maintained above $80 \%$ after 210 days immersion in the water.

- The microstructure of the MOC transformed from needle-like crystals to all gel-like crystals with the addition of fly ash + phosphoric acid + ferrous sulfate + ethyl silicate after the water immersion. This is mainly because of the generation of the magnesium-chloridesilicate-hydrate gel (M-Cl-S-H gel) and the insoluble magnesium-chloride-hydrate gel (M-Cl-S-H gel).

- The transformation of the needle-like crystal to the amorphous gel may be due to the interaction performance and the superposed effect of the fly ash, phosphoric acid, ferrous sulfate and ethyl silicate. The TEOS hydrolysed in water and $\mathrm{H}_{3} \mathrm{PO}_{4}+\mathrm{FeSO}_{4} \cdot 7 \mathrm{H}_{2} \mathrm{O}$ accelerated the hydrolysis that produced more silica. The large quantity of the silica reacted with the softened fly ash that formed not only an insoluble magnesium-chloride-hydrate gel $(\mathrm{M}-\mathrm{Cl}-\mathrm{H}$ gel) but 
also an insoluble magnesium-chloride-silicate-hydrate gel (M-Cl-S-H gel).

- The water shy MOC phases could be mainly protected by the surrounding spherical fly ash particles and the water insoluble $\mathrm{M}-\mathrm{Cl}-\mathrm{S}-\mathrm{H}$ gel and the $\mathrm{M}-\mathrm{Cl}-\mathrm{H}$ gel, thus, inhibited the growth of the brucite in the MOC matrix.

- The optimal dosage of the TEOS was $0.9 \%$ by weight of the $\mathrm{MgO}$ powder in this experiment.

\section{Acknowledgments}

Funding: Financial support from the Special Project Major Project for the Transformation of Scientific and Technological Achievements of Qinghai Province (grant numbers 2018-NN-152 and 2019-GX-165), the Science and Technology Development of Qinghai Province, (grant numbers 2014-GX-A2A and 2015-GX-A1A), the Natural Science Foundation of China (grant number U1507120) and the Youth Innovation Promotion Association CAS (grant numbers 2018467 and 2019423) are gratefully acknowledged.

\section{REFERENCES}

1. Xiao X., Chang C, Zheng W. (2016): Study on mechanical properties of magnesium oxychloride cement concrete pavement. Journal of Salt Lake Research, 3, 50-54.

2. Li Y., Yu H., Zheng L. (2013): Compressive strength of fly ash magnesium oxychloride cement containing granite wastes. Construction and Building Materials, 38, 1-7. doi: 10.1016/j.conbuildmat.2012.06.016

3. Zhou M., Gong Y., Qi Z. (2005): The experimental research on the magnesium oxychloride cement product modified by fly ash. Fly Ash Comprehensive Utilization, 5, 29-31.

4. Wen J., Yu H., Wu Ch. (2013): Hydration kinetic and influencing parameters in hydration process of magnesium oxychloride cement. Bulletin of the Chinese Ceramic Society, 41(5), 588-596. doi: 10.7521/j.issn.0454-5648.2013. 05.03

5. Wen J., Yu H., Xiao X., et al. (2014): Heat release characteristics and mechanical property of thermal decomposition magnesium oxychloride cement. Journal of Central South University:Science and Technology, 12, 4175-4180.

6. Zheng L., Li Y., Yu H., et al. (2013): Effect of pretreatment methods on leaching of free $\mathrm{Cl}^{-}$in magnesium oxychloride cement. Journal of Central South University: Science and Technology, 44(7), 2720-2725.

7. Dong R., Wang M., Zhang Q. (2011): Measurement for the free calcium oxide in dolomine half roasting product Journal of Salt Lake Research, 19(2), 25-28.

8. Zhang C., Yang H., Ma X. (2014): Research progress of magnesium oxychloride cement. Bulletin of the Chinese Ceramic Society, 33(1), 117-121.

9. Wu C., Zhang H. (2013): The effects of alumina-leached coal fly ash residue on magnesium oxychloride cement Advances in Cement Research, 25(5), 254-261. doi: 10. 1680/adcr.12.00019
10. Jin Y., Xiao L., Zhao Y. (2000): Effect of additives on water resistance of magnesium oxychloride cement. Jilin Building Materials, 2, 11-13.

11. Chua C.K., Chan J., Li Z. (2009): Influences of fly ash on magnesium oxychloride mortar. Cement and Concrete Composites, 31(4), 250-254. doi: 10.1016/j.cemconcomp. 2009.02.011

12. Shively R.R. (1916): An investigation of composition flooring. Industrial \& Engineering Chemistry, 8(8), 679-682.

13. Li J., Li G., Yu Y. (2008): The influence of compound additive on magnesium oxychloride cement/urban refuse floor tile. Construction and Building Materials, 22(4), 521-525. doi: $10.1016 /$ j.conbuildmat.2006.11.010

14. Deng D. (2008) The mechanism for soluble phosphates to improve the water resistance of magnesium oxychloride cement. Cement and Concrete Research, 33 (9), 1311-1317. doi: 10.1016/S0008-8846(03)00043-7

15. Li Y., Li Z., Pei H., Yu H. (2016): The influence of $\mathrm{FeSO}_{4}$ and $\mathrm{KH}_{2} \mathrm{PO}_{4}$ on the performance of magnesium oxychloride cement. Construction and Building Materials, 102, 233-238. doi: 10.1016/j.conbuildmat.2015.10.186

16. Zhang X. (2018). Study on compound modified MOC material and its application in thermal insulation board. Thesis. Henan, Xinyang Normal University. (in Chinese)

17. Dong J., Yu H., Zhang L. (2010): Study on experimental conditions of hydration methods of determining active magnesium oxide content. Journal of Salt Lake Research, $18,38-41$.

18. Huang Q., Xiao X., Li Y. (2018) Research on the properties of magnesium oxychloride cement prepared with simulated seawater. Advances in Cement Research, 30(7), 277-284. doi: 10.1680/jadcr.17.00127

9. 1Huang Q., Li Y., Zheng W. (2019): Investigation on the properties of magnesium oxychloride cement prepared by seawater. Advances in Cement Research, doi: 10.1680/ jadcr.18.00159.

20. He P., Poon C.S., Tsang D.C.W. (2017): Effect of pulverized fuel ash and $\mathrm{CO}_{2}$ curing on the water resistance of magnesium oxychloride cement (MOC). Cement and Concrete Research, 97, 115-122. doi: 10.1016/j.cemconres. 2017.03.005

21. He P., Poon C.S., Tsang D.C.W. (2017): Using incinerated sewage sludge ash to improve the water resistance of magnesium oxychloride cement (MOC). Construction and Building Materials, 147, 519-524. doi: 10.1016/j.conbuildmat.2017.04.187

22. Fernández-Jiménez A., Palomo A. (2015): Composition and microstructure of alkali activated fly ash binder: effect of the activator. Cement and Concrete Research, 35 (10), 1984-1992. doi: 10.1016/j.cemconres.2005.03.003

23. Tan Y., Liu Y., Grover L. (2014): Effect of phosphoric acid on the properties of magnesium oxychloride cement as a biomaterial. Cement and Concrete Research, 56, 69-74. doi: 10.1016/j.cemconres.2013.11.001

24. Xia S., Xing P., Gao S. (1991): Studies on the basic compounds of magnesia cement: the thermal behaviour of magnesium oxychlorides. Thermochimica Acta, 183, 349-363. doi: 10.1016/0040-6031(91)80471-T

25. Li D. (2007): Preparation and characterization of silica nanoparticles. Chemical Engineer, 21(8), 63-64. 